\title{
Smart Cart With Multi-shopping Solutions
}

\author{
https://doi.org/10.3991/ijim.v15i24.26397 \\ Tarig Faisal $^{(凶)}$, Moath Awawdeh, Daniel Habte, Hala Berhanu, Kibrom Kifle, \\ Lia Misghina, Anees Bashir \\ Higher Colleges of Technology, Al Ruwais City, Abu Dhabi, UAE \\ tfaisal@hct.ac.ae
}

\begin{abstract}
Consumerism has constantly been growing, and visiting marketplaces, and purchasing is a key development factor for the economic development of a city. The spending habits of people are a reflector of many development indices. As people go out for purchasing in malls for shopping essential items, they often tend to find long queues at the billing counter, and the queues are more longer during weekends and during sale seasons. This has been deterring people from going out shopping and instead resort to online shopping. This has affected the sales and revenue of departmental chains. Also, people spend quite a considerable amount of time searching through rows in order to find the items of their choice. Proposing a solution to these above-mentioned problems using technology is a real boon. Installing a payment option on the cart itself would result in cutting down the waiting times in queues. Moreover, the customers can also benefit from navigation through the virtual maps that would be displayed on the screens of the carts. This reduces the time wasted by customers in searching for products. Hence the customers are self-dependent during their shopping. For the retail group, their transactions and management are truly simplified with these developments. Additionally the counter labor will decrease if not cease to zero, which in turn reduces the labor cost drastically. In times of pandemic like now, people have been sticking with online shopping due to various reasons, but they long to go out and spend times in the malls as they would in normal times. The proposed solution would definitely assist in the normalization of lives and bring back on ground retail back to life.
\end{abstract}

Keywords — barcode reader, radio frequency identification, smart gate, smart shopping gate

\section{Introduction}

Technology has been a key player in influencing various walks of our lives, including but not limited to environmental and health monitoring, industrial developments, entertainment. Consumer trends have been impacted widely using technology, and online shopping has turned out to be one of the top fads of the millennials for buying nonperishable items and electronic goods. People still flock to supermarkets and shopping malls to stock on groceries and other needs. Consumers tend to like the control they have during physical shopping, where they can choose, pick and feel items of their choice, 
which is unavailable to consumers during online shopping. Customers go searching inside the shop to pick the items that they need, which in turn can elongate the shopping process and make the customers feel exhausted. Research has shown that shopping environments can evoke emotional responses in consumers, and these emotions, can, in turn, influence the shopping behaviors and outcomes [1]. Some of the main problems associated with shopping are discussed. Firstly, locating a specific item of choice in the racks of the malls is a huge task considering the fact that shopping malls can be quite extensive in size. Customers tend to search for some distinct, not so common items at every nook and corner of the mall, which consumes a lot of time and is physically exhausting. Secondly, the probability of overcrowding at billing counters at shopping malls is another factor that makes the customers drained. The queues tend to get much longer during the busy times of the year like weekends, festive seasons, and during a sale, where average waiting time of the queue tends to increase considerably which becomes where uncomfortable for the customers. Thirdly, the malls employ workers at every counter to scan the items purchased and to facilitate the payment of bills. One of the famous approaches is the introduction of self-checkouts, by which customer convenience has been improved drastically [2]. But an extra cost is being involved in this method which can increase the prices of the item. These problems tend to persist, although there has been a significant technological improvement made in them over time. The need for a simplified and effortless lifestyle has been the preferred choice. According to Gandalfo Dominici [3], the implementation of smart shopping carts will positively influence customer attitude as it creates a more convenient shopping experience for the customers than the previous methods. Therefore, the Smart Shopping Cart (SSC) will be a great transformation and will provide a favorable solution to both sides of the business stakeholders. Improving the time utilization while saving up on the expenditure would be beneficial and pleasing to everyone involved in the process. The SSC technology would have the benefits of both auto payment and navigation systems. The system would enable the customer to self-pay bills and would assist them in searching for items through a navigation map without any external help.

Several systems have been developed linking RFID and Barcode technology. Previous research on the design of the smart shopping system mainly focuses on using low/high-frequency RFID [4-10]. Klabjan et al. [11] proposed the idea of tracking a customer in a store, creating a database with the information and observe the customer choice and preferences so that stores can create and offer personalized coupons and discounts based on the customer's taste. Some significant proposals have been made in the areas of smart shelves and smart carts. Smart shelves can oversee the location and status of the items, and smart carts are implemented using RFID technology. Details pertaining to every product on the shelves and information related to the customers are uniquely identified by using RFID. A customer authenticated by the system can choose the products from the list displayed on the user interface [12]. Similarly, Li et al. [13] propose the usage of sensors on the grocery shelf to keep up to date with the category and number of items to the central server so that the server keeps count of the items' status in the store and can send timely updates to the inventory specialist team as and when required. Furthermore, this would ease out the process that are involved in the inventory management as all the items can be automatically read by an RFID reader instead of being manually scanned by an employee at the store. According to [14], 
barcode scanner and touchscreen display are attached to the cart, which can be used to scan the products and display the product information, cost, and total bill. The customer can then pay the bill through any one of the online payment modes such as Paytm, UPI, Phone Pay, etc.

Wang et al. [15] have developed a sales-promotion application, in which each cart checks if the customer has an interest in some products and displays related sales information to the product to increase the customer's desire for buying. Likewise, Popa et al. [16] demonstrate the utilization of CCTV to detect motion patterns such as walking, monitor eye movements that look at products, and touch products, to categorize customers by their behavior. Both studies [17], [18] associate products with passive RFID tags to detect their movement caused by customers. Thus, the retailer can find out products that are popular among customers or the products which catch the attention of the customers. However, these systems lack interaction with the customers. Based on the study presented [19], a person-following robotic cart controlled via a smartphone application has been designed. The robot cart is aided by the ultrasonic sensor to detect and avoid an obstacle. The user controls the movement, speed and direction of the cart using a mobile app. This facilitates advantages for both business owners and customers.

In general, the main issues that have been discussed in the above studies include the time consumed by shoppers in finding their items and the payment process. Additionally, during this current COVID19 pandemic time, these factors along with the multiple interactions between the shoppers and the retail's employee handling items during purchasing have significantly impacted both consumer and employee safety. Given these lacunae, this study proposes a complete smart shopping cart that overcomes the mentioned issues which benefits both the customers and the retail chain.

The main contributions of the proposed system include the development of A realtime smart shopping cart that minimized the shopping time process and ensures the selection of the best quality of the items, limited interaction between customers and supermarket employee that could be accrued through items handling which maintain safety precautions for the customers and employee, two-channel items check included in the cart and for the supermarket exit to ensure security measures of the items, customers membership cards that assist customers in their payment without exhausting time and energy in queues, Online Customers service assistance to assist customers with any required purchasing services, and finally a management system that assists supermarkets in immediate update of their products as well as auto-payment of the items.

The remainder of this paper is structured as follows: section two discusses the proposed system and its functionality. The third section presents the circuit diagram of the system as well as the system operation flowchart. The results of the hardware and software implementations of the developed system and the comparison with the existing system are shown in the fourth section. Finally, the conclusion is drawn in the last section.

\section{Proposed system}

In general, the system is developed to assist customers in performing their shopping process in the supermarket in minimum time with minimum effort. The system is 
developed in a way that if a customer wants to purchase an item, the customer has to pick the product and scan its barcode and then place it in the cart. Corresponding item details are displayed on the cart screen. Additionally, if the customer requires further information, such as the location of any item or customer services assistant, the customer can get that information from the cart screen. After the customer completes the purchase, the customer can obtain the bill from the cart and uses the membership card for the payment without the need to perform payment in the counter or cashier. Finally, the customer leaves the supermarket from a dedicated gate. Accordingly, the proposed Smart Shopping Cart system comprises three main parts, namely the carts (clients), server, and Smart Gate as shown in Figure 1.

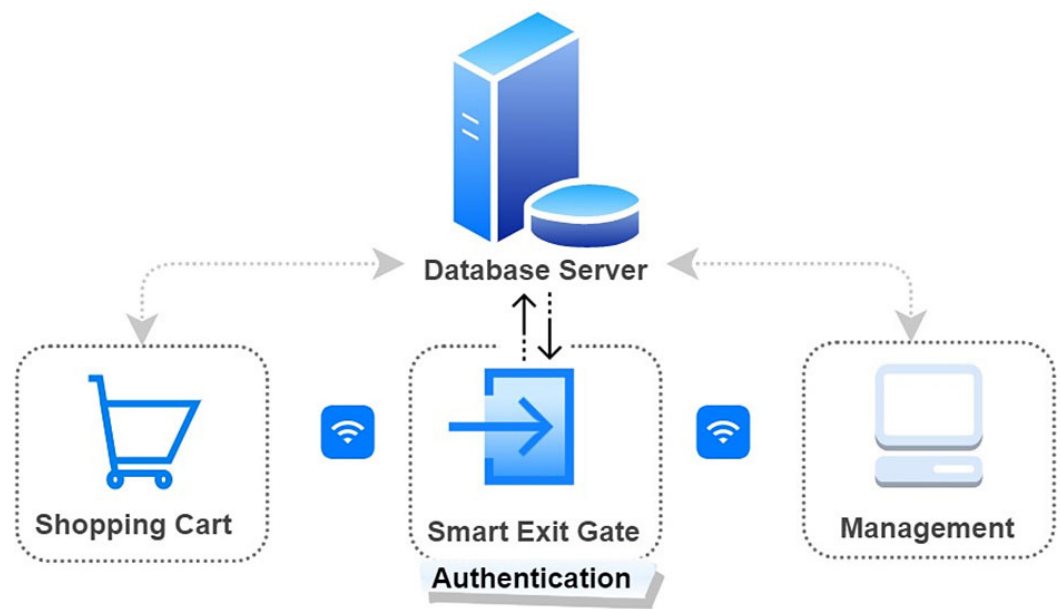

Fig. 1. Block diagram of the overall system

The smart cart is the main element of which the customers are interacting with and its equipped with all necessary devices. Each cart system has many inputs/output interfaces to communicate with peripheral devices using a microcontroller. The cart inputs are barcode reader, weight sensor, RFID reader, and costumers card while the LCD screen is considered as an input and output device. The primary data input tool is the barcode reader which used to recognize the item's unique barcode. The second data input is the weight sensor which is used to measure the weight of each item placed in the cart. Thus, the measured weight is used to compare with the actual weight of the same item registered in the database. The LCD (Liquid Crystal Display) is used to visualize the items details as well as its include some other features such as virtual map of the shop for quick navigation of the items, interactive GUI buttons, and labels which switch between multiple windows and processes any service including customer service calls, check balances, go shopping, map, etc. The customer card data input is used by the customers to make the payment. Finally, the thermal printer is used to print out the receipt depending on the customer's choice. 
All the carts and the smart gates are connected together using the server. Any change made in the server's database can be read by the carts at any instant. Similarly, notification of any item sold through the cart is sent to the server and stored in the database to help the monitoring and keeping track of items in the store. Since server-client communication is the most crucial aspect in monitoring the whole system, the wireless connection (Wi-Fi) is the medium or channel that used for communication.

One of the essential issue in supermarket is the security of the its items since it's a public place. To ensure that security measures are in place to avoid slip some of the items outside the supermarket without payment, anti-theft system is implemented in this project. The system is implemented in two phases; the first phase in the cart itself which was discussed earlier by comparing the sum of the weight of the items in the cart with the weight in the database and secondly by having a smart gate at the exit door. The smart gate is designed based on RFID reader which ensure that the bill is paid before the customers leave the supermarket. The customers need to scan the card that was used for purchasing in the smart gate in order for them to leave the supermarket. The RFID reader included in the smart gate, reads the ID number of the purchasing card and compare it with the server's database then it will allow the customers to go through the smart gate if the bill is confirmed paid from the database.

\section{Circuit diagram and flow chart}

The circuit diagram of the developed system is shown in Figure 2. The circuit comprise of Raspberry Pi 4 microcontroller, Barcode reader, RFID reader, weight sensor, thermal printer, and LCD screen.

As it shown in the figure, the Raspberry Pi 4 microcontroller which programmed via python is used to connect all the peripheral devices. The LCD screen is connected via the HDMI cable, whereas the barcode reader is interfaced by the USB cable. The HDMI cable is used to transmit data from microcontroller to screen, while the USB cable is used to power the screen and transmit data to the microcontroller. The weight sensor (load cell) is connected to the microcontroller through HX711 module. This attachable module is used to amplify the load cell signal. Without this module, the microcontroller would not be able to detect the voltage difference measured from the weight sensor. The RFID reader is connected to the microcontroller microcontroller's GPIO pins directly. Unlike the other devices, the thermal printer demands higher current (around 1 ampere) to generate heat. On the other hand, the microcontroller can be overloaded with this amount of current. In order to resolve this issue, the printer is powered from the battery using a buck converter. Finally, the data wires are connected to the microcontroller GPIO pins. The pins' functions of the Raspberry Pi 4 microcontroller are defined in the program. 


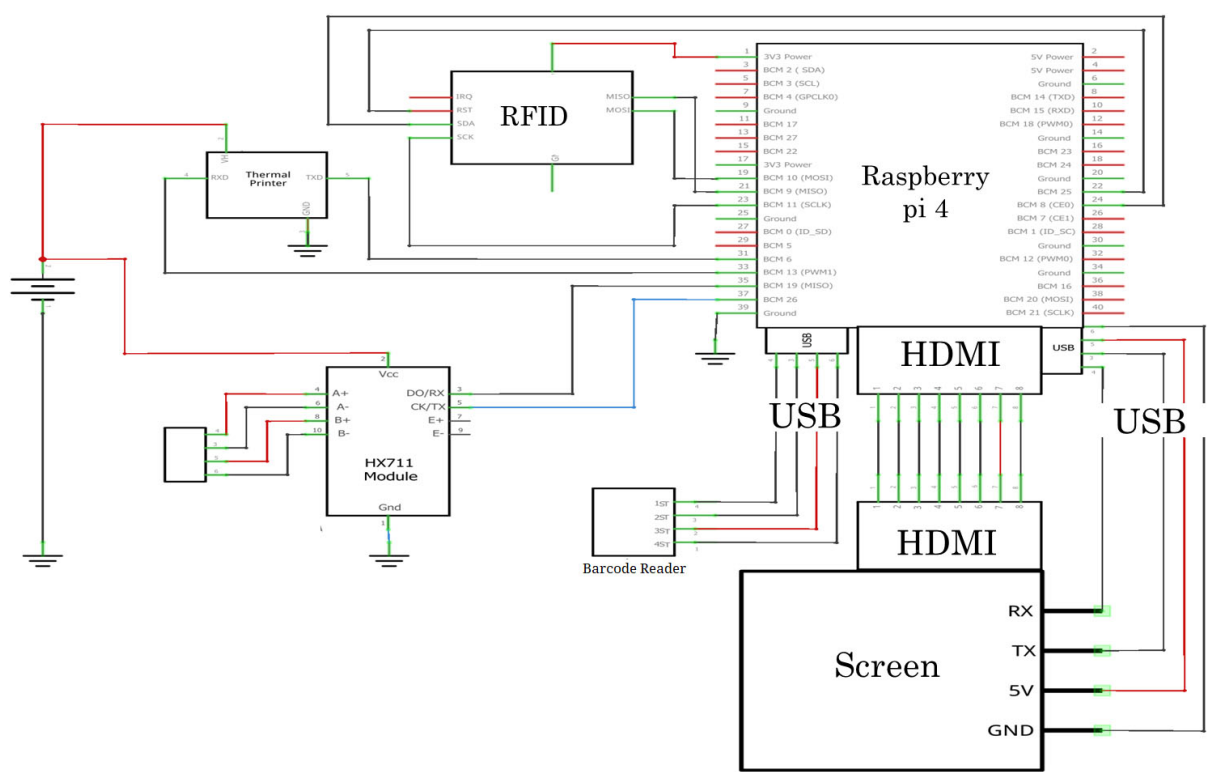

Fig. 2. Circuit diagram of the developed system

Figure 3 shows the flow chart of the developed system. When the cart is powered, the sum of price and weight are initialized as zero. The first process is to read the price and weight of a scanned item. The measured weight is then compared with the actual weight of the item registered in the database. If the compared weights are equal, the total sum of price and weight will be added and wait for the next item to be scanned. This is the default setting. In the case of the customer changes his mind and wants to cancel the scanned item, the "remove item" button is used to interrupt the default flow and subtract the price and weight of the returned item from the total. Moreover, the checkout button is available to end shopping and pay the price. However, if the compared weights are not equal, an error message is displayed to notify the customer that different item is included in the cart. This might happen if the customer purposely intents to bypass the system or by mistake. 


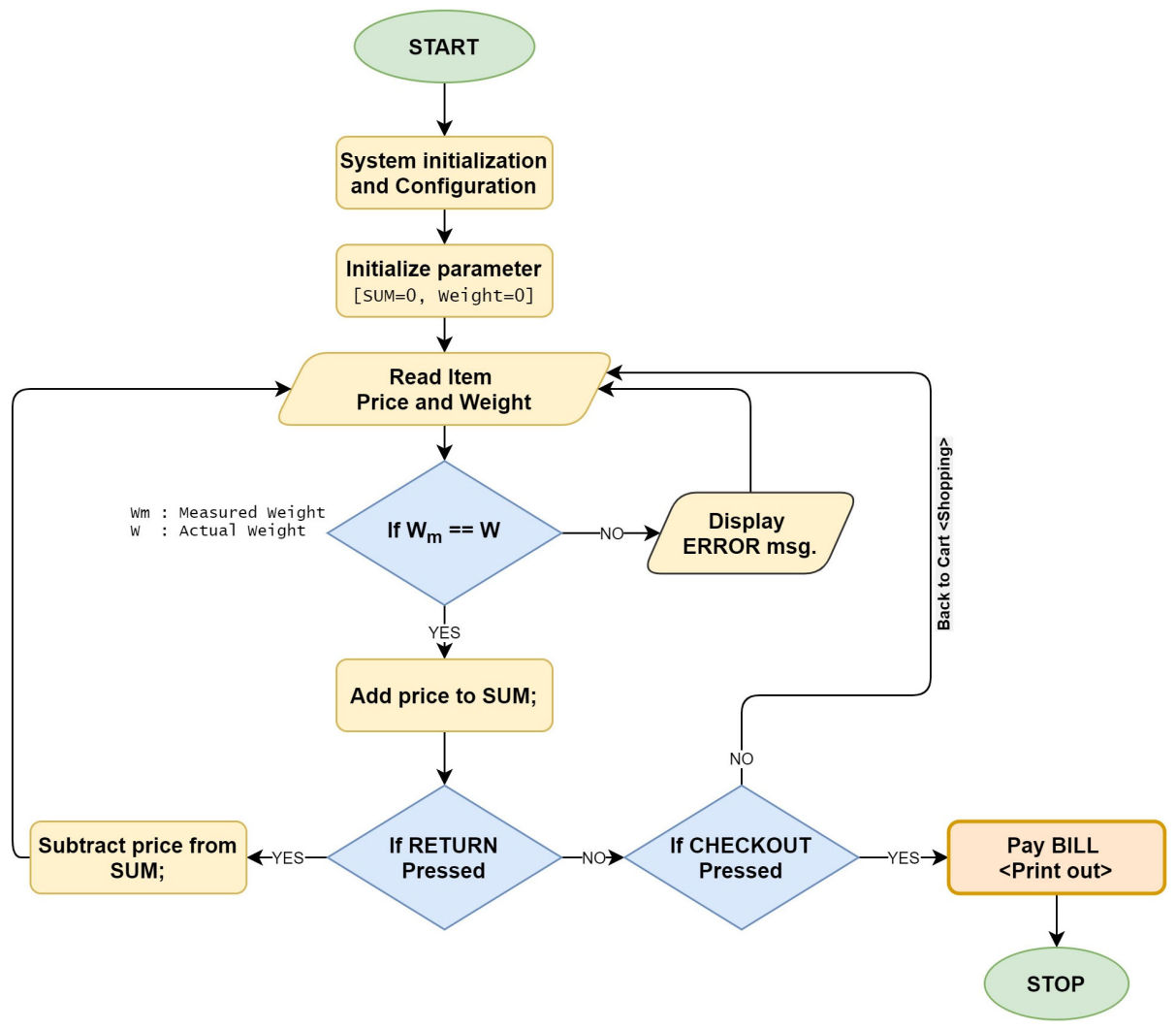

Fig. 3. Flowchart of the developed system

\section{$4 \quad$ Results and conclusion}

\subsection{Developed system}

Figure 4 shows the final working prototype of the developed system. A Seven inches touch LCD screen with a resolution of $1200 \times 600$ pixels is used along with the CSN-A2 thermal printer. The costumer card has an NFC (Near Field Communication) communication capability. The smart cart is powered by a sealed lead acid rechargeable battery. This battery has a capacity of $12 \mathrm{v} 12 \mathrm{Ah}$. But none of the circuit components consume $12 \mathrm{v}$ though they need higher current around $3 \mathrm{~A}$. For example, the Raspberry Pi 4 microcontroller takes $3 \mathrm{~A}$ and $5 \mathrm{v}$ and thermal printer rates at $1 \mathrm{~A}$ and $5 \mathrm{v}$. Therefore, to tackle this issue, a buck converter is used to step down the voltage from $12 \mathrm{v}$ to $5 \mathrm{v}$. The battery can drive the cart for at least 9 hours at a single charge. Moreover, to save power and prolong the battery life, the Raspberry Pi 4 microcontroller stays at sleep mode when it is in idle condition. In addition to that, the printer is powered only when it is printing. Those were accomplished by using MOSFET transistor as a switch to open and close the flow of electrical current. As a result, the printer operates at the fraction of time, which accounts a negligible power consumption as compared to the Raspberry Pi 4 microcontroller. 


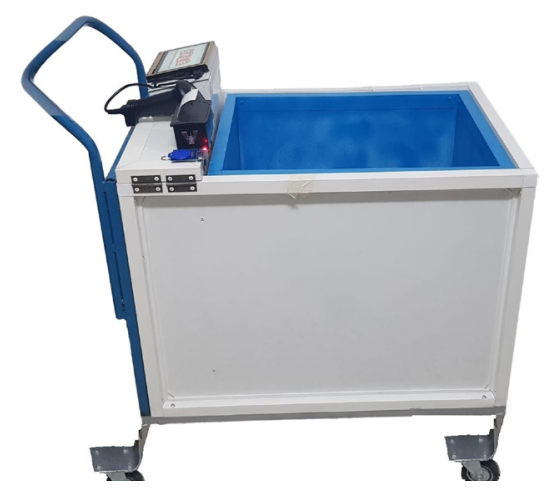

Fig. 4. Prototype of the developed system

The interaction Home page screen and its options is displayed in the LCD as shown in Figure 5. Figure 5a shows the home screen page which includes many buttons such as search button for the users to search for any item location as shown in Figure 5b, the balance check option in Figure 5c, and Set budget in Figure $5 \mathrm{~d}$. The budget set button assists the customers to stay within their budget by setting the maximum limit they need to spend.

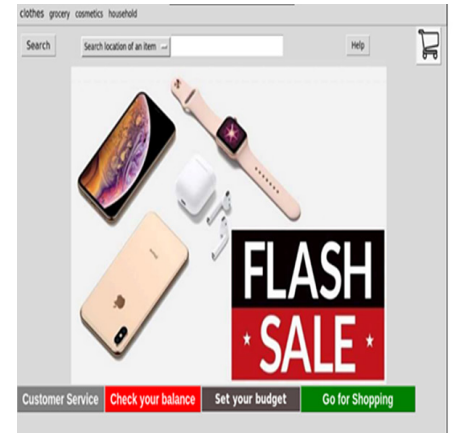

a. Home page

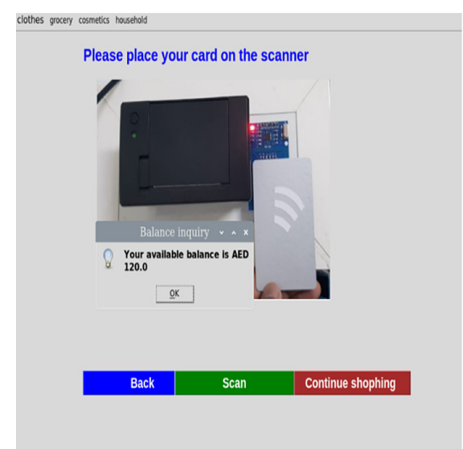

c. Check Balance

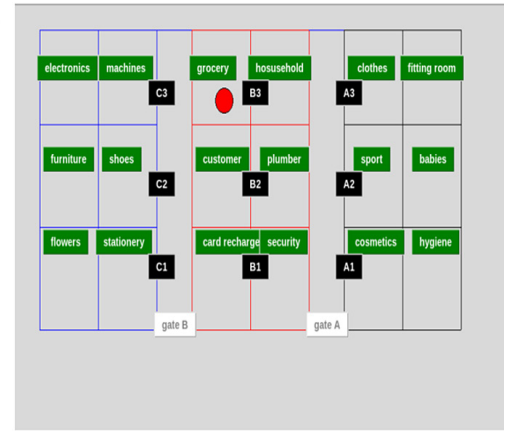

b. Items location Map

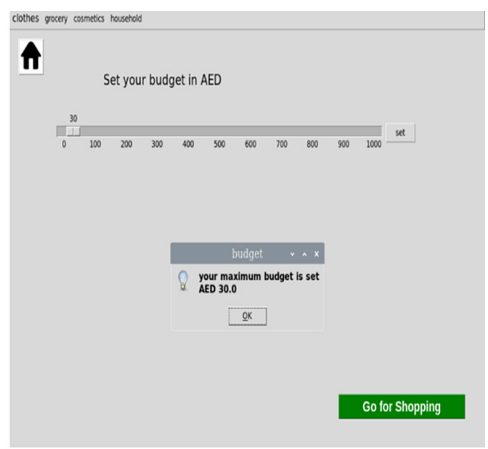

d. Set Budget

Fig. 5. Home screen and its options

The shopping process phase starts by pressing start shopping's button of which a new window will be opened and customers can start their shopping by scanning the 
items barcode using the barcode scanner as shown in Figure 6. Then the item is placed in the cart. Secondly, the system starts searching for the items scanned barcode in the server's database to identify the matching item. If the item is found in the database, then the weight of the item placed in the cart is compared with the item in the database. If the weight of the items placed in the cart is matched the database, then the name alongside with its price will be listed, as shown in Figure 6a. However, if the weight of the item recorded in the database and weight measured at the cart are different, the system notifies the customer that item included in the card is different from the one scanned as shown in Figure 6b.

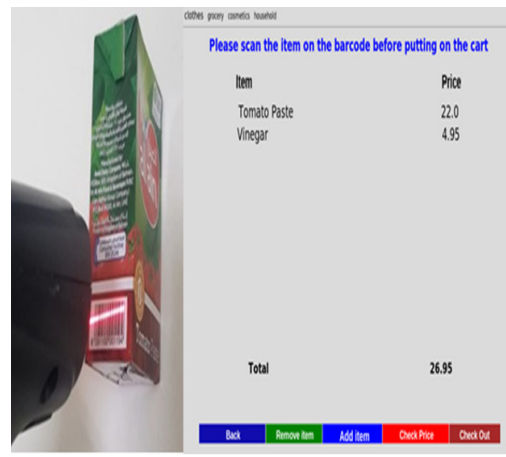

a. Right item added to the cart

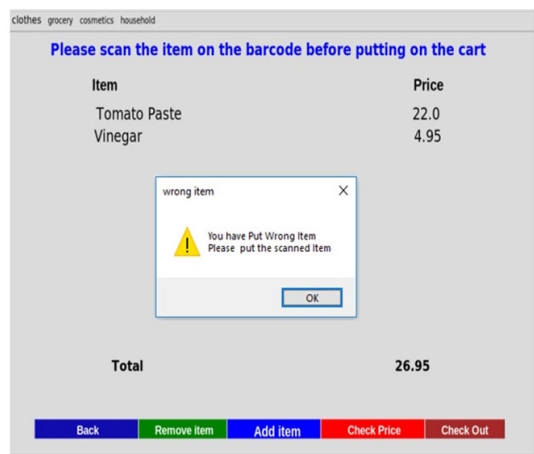

b. Wrong item added to the cart

Fig. 6. Items scanning

If the price of the selected item within the set budget as shown in Figure $7 \mathrm{a}$, the customers can proceed with their shopping, however if the budget limit is reached, no further item can be added as shown in Figure $7 \mathrm{~b}$.

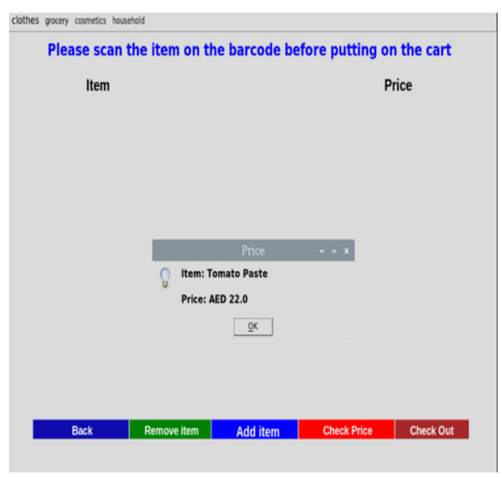

a. Within the set budget

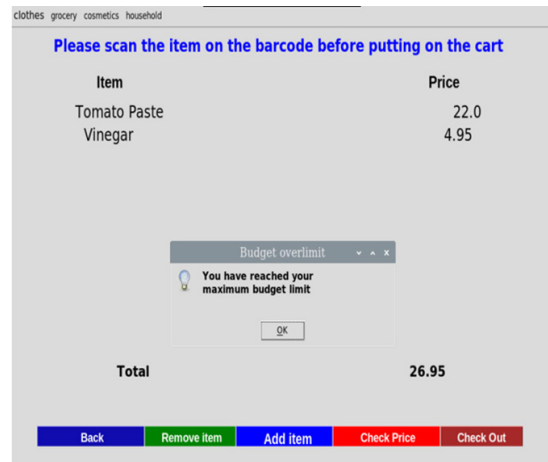

b. Maximum budget reached

Fig. 7. Price check

After scanning each item completed, the customers have five scenarios; First, to add another item to the cart by scanning their barcodes; Second, to go back to the home screen for another task while the scanned items are saved; Third, to remove an item from the cart; Fourth, check the price (this can be used if a customer wants to check 
the price only); and Fifth, exit the shopping and check out. It worth to mention that to remove an item, the return button should be pressed in the screen then the selected item that need to be removed from the cart is scanned. Subsequence the price of this item will be subtracted from the total.

The payment process phase starts by pressing the pay button and scanning the NFC card as shown in Figure 8. If the total amount to be paid is lower than the balance in the NFC card as shown Figure 8a, the payment will be completed. However, if the balance in the NFC card is insufficient to do the payment, the customer cannot proceed with the payments and a warning sign will be displayed, as shown in Figure 8b.

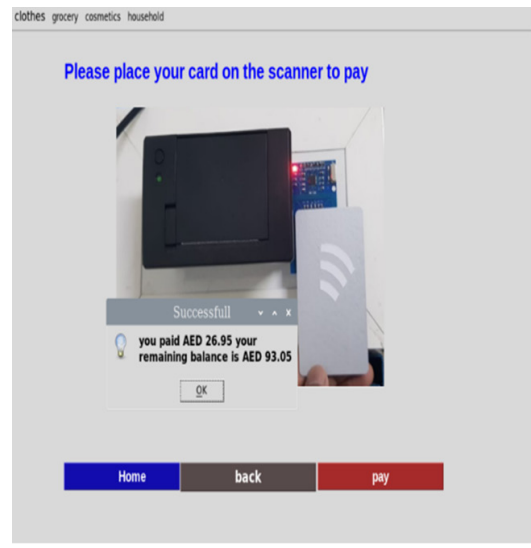

a. Within the set budget

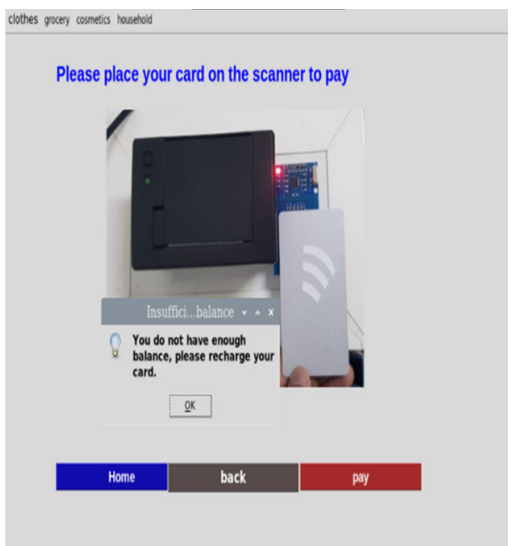

b. Maximum budget reached

Fig. 8. Payment process

Once the payment is made successfully, the customer gets his receipt from the thermal printer mounted on the cart, as shown in Figure 9a.

Figure $9 \mathrm{~b}$ shows the proposed design of the smart gate. Since the developed system in the prototype phase we have included the smart gate feature in the system programing part and it was tested using RFID reader.

In order for the customers to exit from the smart gate, the NFC card need to be scanned in the smart gate. The NFC card information is compared with the database in the server and then the smart gate will be opened if the bill is paid.

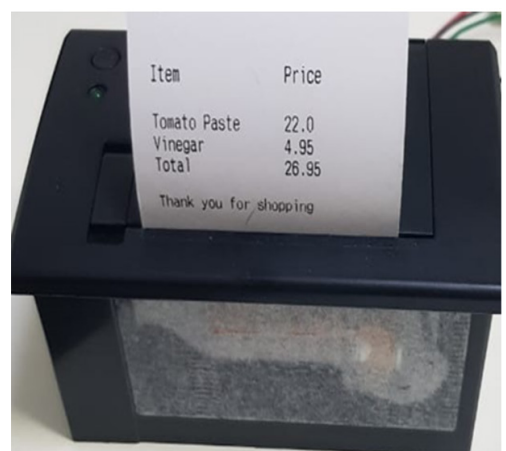

a. Printer printing receipt

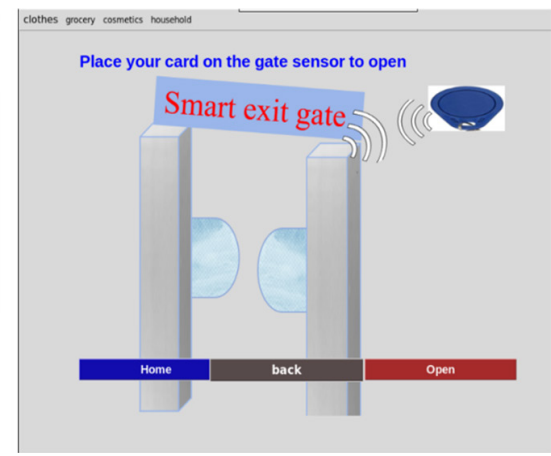

b. Accessing smart gate using NFC card

Fig. 9. Existing process 
If customers face any difficulties and need any assistant, the customer services button is used. The main purpose of the button in to contact the authorized person to assist the customer issue. As shown in Figure10a, when this button is pressed, it redirects to another window to identify the type of assistant needed. Then the current location of the cart must be selected to get immediate assistance as shown in Figure 10b.

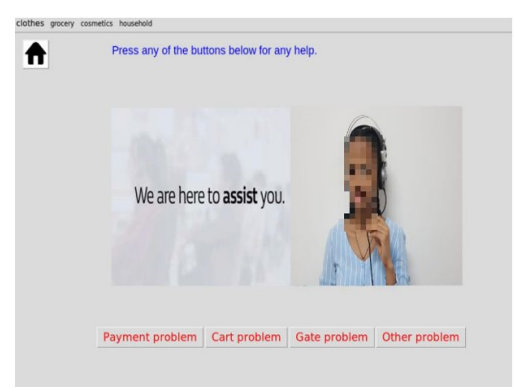

a. Customer service main page

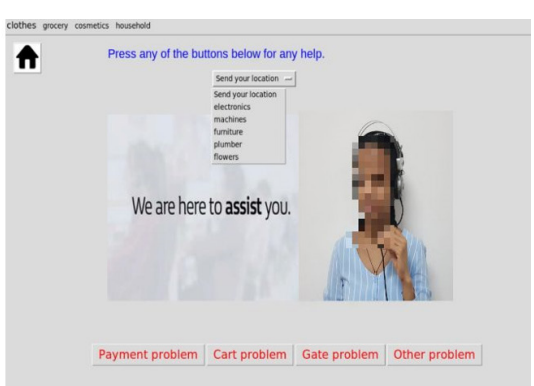

b. location identification option

Fig. 10. Customer service

The items detail that displayed in the cart are extracted from the central server database. The structure of the database is shown in Figure 11.

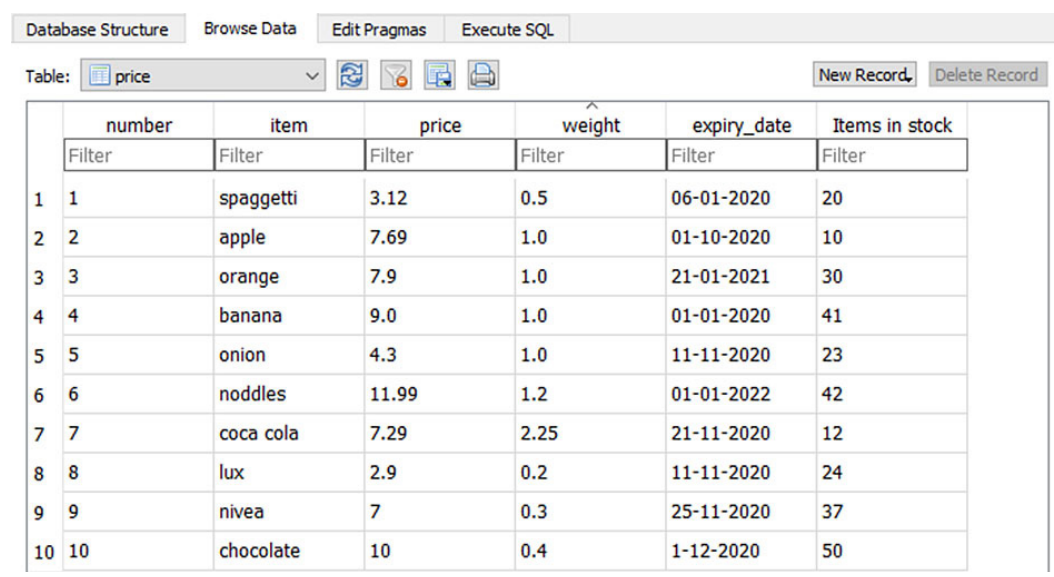

Fig. 11. Database structure

The management of the items details in the database is accomplished through a designed GUI which shown in Figure 12. Adding, updating, or deleting item from the database can be done easily through the developed GUI as shown in Figures 12a and $12 \mathrm{~b}$. 


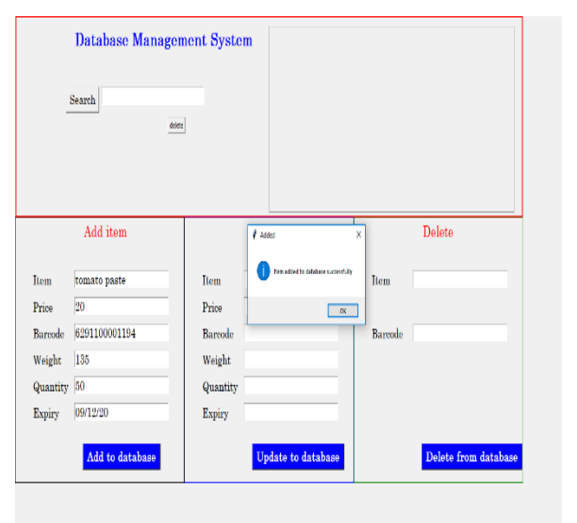

a. Adding items

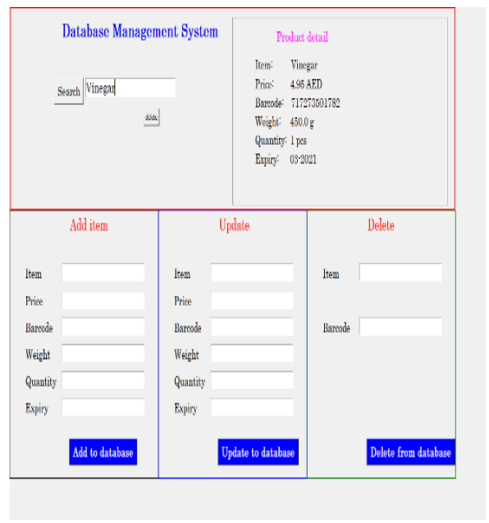

b. Verifying items

Fig. 12. Database management interface

\subsection{Comparisons with existing systems}

Table 1 features the comparison between the proposed system and other existing developed systems. The design features and the services included in those systems are the main points for the comparison. Firstly, in the design feature, LCD and hand phone devises are the main tools used for the display while Arduino based technology is used for selecting the microcontroller. The communications with the main server is accomplished either by using WiFi or ZigBee modules. Secondly different types of services are included on those systems. In terms of bill payment, most of the developed systems generate the bills in the smart cart and those bills are paid by the costumers in the cashiers or in the counter. To eliminate waiting and queues time for bill payment, our system and Berdaliyev et al., 2016 [28] system used a reloadable card to perform the payment. Reducing the obstacles and difficulties for customers to find the product location by identifying its location, is developed only in our system and Shahroz, et al., 2020 [20]. Anti-Theft is incorporated in three system including our system. Its usually designed utilizing the RFID reader in the exit gate. However, in our system we have include extra measure which can alert the customers if they placed any item in the cart without scanning it by comparing the total weight of the items in the cart with the total weight in the bill. Finally, since our system is full automated, it's the only system which can facilitate customer service assistance to the customers if they face any difficulties with the services. If all those features are considered in addition to the fact that our system is implemented in hardware, we can conclude that our system is more reliable and convenient to be used by the customer and the shop owners. 


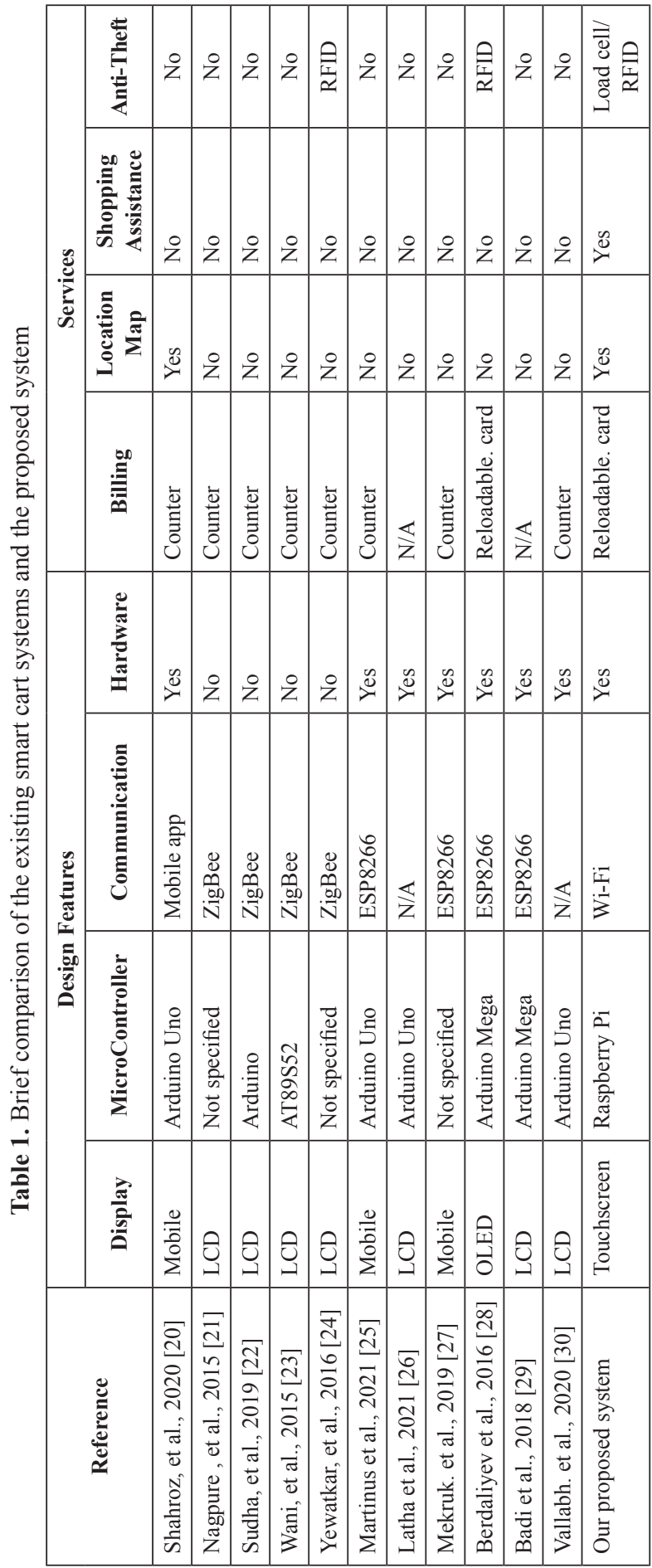




\section{Conclusion}

To enhance shopping experience for customers and to utilize their time effectively, the proposed solution can be implemented. Accessing shopping malls relatively becomes more effortless for customers, and their management becomes easier for the business proprietor. Customers can get a huge relief from waiting in queues for billing their items, and also can locate items of their choice easily without wasting time using a position allocation and retrieval system. The business can also reduce the workforce being employed at billing counters, and they could be shifted to other departments to improve customer satisfaction and engagement. Having all the interfaces implement of the shopping cart would be an exclusive and exciting experience for the shoppers and can improve the business operation restructuring. The efficiency of the system will be remarkable when introduced in a situation like now, where social distancing and contactless payments are practiced widely.

\section{Acknowledgment}

The authors would like to thank the reviewers and collaborators for their valuable comments and suggestions to improve the quality of the project. This paper is based on a project that has been supported by the Higher College of Technology (HCT), UAE.

\section{$7 \quad$ References}

[1] K. A. Machleita, AbstractResearch, "Describing and measuring emotional response to shopping experience", Journal of Business Research, 11 Jul 2000. [Online]. Available: https:// www.sciencedirect.com/science/article/abs/pii/S0148296399000077. [Accessed Oct. 3, 2019].

[2] K. Peik, T. Shiang-Yen, N. L. Abdullah, R. Idrus, "Integrated study of automated checkout shopping trolley." Available: https://www.semanticscholar.org/ paper/Integrated-Study-of-Automated-Checkout-Shopping-Peik-Shiang-Yen/ fc5flacb3066bb8b21bc1cda9ef5f5be20b9a10c

[3] G. Dominici, M. Matic, T. Abbate, D. D. Fatta, "Consumer attitude toward using smart shopping carts", International Journal of Electronic Marketing and Retailing, vol. 7, no. 3, pp. 229-243, 2016. Available: https://www.researchgate.net/publication/307466528 Consumer attitude toward using smart shopping carts a comparative analysis of Italian and Croatian_consumer_attitudes. [Accessed Dec. 2, 2020]. https://doi.org/10.1504/ IJEMR.2016.078952

[4] Mohamed El Beqqal, Mostafa Azizi, "Taxonomy on IoT technologies for designing smart systems", International Journal of Interactive Mobile Technologies, vol. 12, no. 5, pp. 182191, 2018. DOI: https://doi.org/10.3991/ijim.v12i5.8831

[5] R. Kumar, K. Gopalakrishna, K. Ramesha, "Intelligent shopping cart", International Journal of Engineering Science and Innovative Technology, vol. 2, no. 4, pp. 499-507, 2013. Available: https://www.semanticscholar.org/paper/Intelligent-Shopping-Cart-KumarGopalakrishna/85ee37b8c78c2611b0fac29ecfd67ca6a800919e. [Accessed Jan. 28, 2021].

[6] Naseer A. Hussien, Saif A. Alsaidi, Iman K. Ajlan, "Smart shopping system with RFID technology based on internet of things", International Journal of Interactive Mobile Technologies (iJIM), vol. 14, no. 4, pp. 17-29, 2020. DOI: https://doi.org/10.3991/ijim.v14i04.13511 
[7] Z. Ali, R. Sonkusare, "RFID based smart shopping and billing", International Journal of Advanced Research in Computer and Communication Engineering, vol. 2, no. 12, pp. 4696-4699, 2013. Available: https://ijarcce.com/wp-content/uploads/2018/12/IJARCCE. 2018.71132.pdf. [Accessed Jan. 29, 2021].

[8] P. Chandrasekar, T. Sangeetha, "Smart shopping cart with automatic billing system through RFID and Zigbee", Information Communication and Embedded Systems (ICICES) 2014 International Conference on, pp. 1-4, 2014. Available: https://ieeexplore.ieee.org/stamp/ stamp.jsp?tp=\&arnumber=7033996. [Accessed Feb. 2, 2021]. https://doi.org/10.1109/ ICICES.2014.7033996

[9] M. R. Sawant, K. Krishnan, S. Bhokre, P. Bhosale, "The RFID based smart shopping cart", International Journal of Engineering Research and General Science, vol. 3, no. 2, pp. 275-280, 2015. Available: https://pnrsolution.org/Datacenter/Vol3/Issue2/40.pdf. [Accessed Jan. 20, 2021].

[10] A. Yewatkar, F. Inamdar, R. Singh, A. Bandal et al., "Smart cart with automatic billing product information product recommendation using RFID \& Zigbee with anti-theft", Procedia Computer Science, vol. 79, pp. 793-800, 2016. Available: https://www.sciencedirect.com/ science/article/pii/S1877050916002386. [Accessed Jan. 20, 2021]. https://doi.org/10.1016/j. procs.2016.03.107

[11] D. Klabjan, J. Pei, “In-store one-to-one marketing”, Journal of Retailing and Consumer Services, vol. 18, no. 1, pp. 64-73, 2011. Available: http://users.iems.northwestern.edu/ peipauj/121.pdf. [Accessed Jan. 20, 2021]. https://doi.org/10.1016/j.jretconser.2010.09.012

[12] P. K. G, S. B. Bangre, K. M, V. M, A. R, "Smart-cart for smart-cities," 2018 Second International Conference on Advances in Electronics, Computers and Communications (ICAECC), Bangalore, 2018, pp. 1-5. Available: https://ieeexplore.ieee.org/stamp/stamp.jsp?tp=\&arnumber $=8479485$. [Accessed Jan. 20, 2021].

[13] R. Li, T. Song, N. Capurso, J. Yu, X. Cheng, "IoT applications on secure smart shopping," 2016 International Conference on Identification, Information and Knowledge in the Internet of Things (IIKI), Beijing, 2016, pp. 238-243. Available: https://ieeexplore.ieee.org/stamp/ stamp.jsp?tp=\&arnumber=7932080. [Accessed Jan. 20, 2021]. https://doi.org/10.1109/ IIKI.2016.25

[14] V. V, P. K. P, C. Reddy S, "Smart shopping cart," 2018 International Conference on Circuits and Systems in Digital Enterprise Technology (ICCSDE), Kottayam, India, 2018, pp. 1-4. Available: https://ieeexplore.ieee.org/stamp/stamp.jsp?tp=\&arnumber=8821103. . Accessed Jan. 20, 2021]. https://doi.org/10.1109/ICCSDET.2018.8821103

[15] Y. Wang, C. Yang, "3S-cart: A lightweight, interactive sensor-based cart for smart shopping in supermarkets," IEEE Sensors Journal, vol. 16, no. 17, pp. 6774-6781, Sept.1, 2016. Available: https://ieeexplore.ieee.org/stamp/stamp.jsp?tp=\&arnumber $=7501897$. [Accessed Jan. 20, 2021]. https://doi.org/10.1109/JSEN.2016.2586101

[16] M. Popa et al., "Analysis of shopping behavior based on surveillance system", Proc. IEEE Int. Conf. Syst. Man Cybern. (SMC), pp. 2512-2519, Oct. 2010. Available: https://www. researchgate.net/publication/220755406_Analysis_of shopping_behavior_based_on_surveillance system. [Accessed Jan. 20, 2021]. https://doi.org/10.1109/ICSMC.2010.5641928

[17] M. C. Popa, L. J. M. Rothkrantz, C. Shan, P. Wiggers, "Assessment of customers' level of interest”, Proc. 19th IEEE Int. Conf. Image Process. (ICIP), pp. 41-44, Sep./Oct. 2012. Available: https://ieeexplore.ieee.org/stamp/stamp.jsp?tp=\&arnumber=6466790. [Accessed Jan. 20, 2021]. https://doi.org/10.1109/ICIP.2012.6466790

[18] J. Han et al., "CBID: A customer behavior identification system using passive tags", Proc. IEEE 22nd Int. Conf. Netw. Protocols (ICNP), pp. 47-58, Oct. 2014. Available: https://www. researchgate.net/publication/285637560 CBID A Customer Behavior Identification System_Using_Passive_T. [Accessed Jan. 20, 2021]. https://doi.org/10.1109/ICNP.2014.26 
[19] N. A. Rawashdeh, R. M. Haddad, O. A. Jadallah, A. E. To'ma, “A person-following robotic cart controlled via a smartphone application: design and evaluation," 2017 International Conference on Research and Education in Mechatronics (REM), Wolfenbuttel, 2017, pp. 1-5. Available: https://ieexplore.ieee.org/stamp/stamp.jsp?tp=\&arnumber=8075245. [Accessed Jan. 20, 2021]. https://doi.org/10.1109/REM.2017.8075245

[20] M. Shahroz, M. F. Mushtaq, M. Ahmad, S. Ullah, A. Mehmood, G. S. Choi, "IoT-Based Smart Shopping Cart Using Radio Frequency Identification," IEEE Access, vol. 8, pp. 68426-68438, 2020. Available: https://ieeexplore.iee.org/stamp/stamp.jsp?tp=\&arnumber=9060814. [Accessed Feb 15, 2021]. https://doi.org/10.1109/ACCESS.2020.2986681

[21] S. Nagpure, P. Sawant, M. Mhaske, B. Nair, "Intelligent shopping trolley and billing system," Tech. Rep., 2018, pp. 72-74. Available: http://ijaseat.iraj.in/paper_detail.php?paper_id=14277\&name=Intelligent_Shopping_Trolley and Billing_System based on_IoT [Accessed Jan. 20, 2021].

[22] P. Sudha, R. Basri, Shobha, Shajahan, T. Babu, "RFID based intelligent trolley system using Zigbee," JETIR, vol. 6, no. 3, pp. 345-350, 2019. Available: https://www.jetir.org/papers/ JETIRAK06069.pdf. [Accessed Jan. 20, 2021].

[23] A. Wani, K. Thakur, N. Vaze, M. Vadhel, P. R. Advirkar, "RFID based intelligent trolley system using ZigBee," Int. J. Eng. Comput. Sci., vol. 4, no. 3, pp. 10886-10889, 2015. Available: http://www.ijecs.in/index.php/ijecs/article/view/1036. [Accessed Feb 15, 2021].

[24] A. Yewatkar, F. Inamdar, R. Singh, Ayushya, A. Bandal, "Smart cart with automatic billing, product information, product recommendation using RFID \& Zigbee with anti-theft," Procedia Computer Science, vol. 79, pp. 793-800, 2016. Available: https://linkinghub.elsevier.com/retrieve/pii/S1877050916002386. [Accessed Feb 15, 2021]. https:// doi.org/10.1016/j.procs.2016.03.107

[25] Martinus, M. Wahab, Yudi, H. Ham, "Data transmission using RFID system on smart shopping carts for checkout process efficiency in supermarket at Indonesia," Procedia Computer Science, vol. 179, pp. 902-912, 2021. Available: https://www.researchgate.net/ publication/349489872_Data_Transmission_Using_RFID_System_on_Smart_Shopping Carts_for_Checkout_Process_Efficiency_in_Supermarket_at_Indonesia. [Accessed Feb 15, 2021]. https://doi.org/10.1016/j.procs.2021.01.080

[26] G. Latha, J. Kandhasamy, S. Sridhar, "Smart shopping cart by RFID technology," Materials Today: Proceedings, 2021, https://doi.org/10.1016/j.matpr.2021.01.253. Available: sciencedirect.com/science/article/pii/S2214785321003424. [Accessed Feb 21, 2021].

[27] S. Mekruksavanich, "Design and Implementation of the Smart Shopping Basket Based on IoT Technology," $14^{\text {th }}$ International Joint Symposium on Artificial Intelligence and Natural Language Processing (iSAI-NLP), pp. 1-6, 2019. Available: https://ieeexplore.ieee.org/document/9045336. [Accessed Feb 21, 2021]. https://doi.org/10.1109/ iSAI-NLP48611.2019.9045336

[28] Y. Berdaliyev, A. P. James, "RFID-Cloud smart cart system," 2016 International Conference on Advances in Computing, Communications and Informatics (ICACCI), 2016, pp. 2346-2352. Available: http://toc.proceedings.com/32058webtoc.pdf. [Accessed Feb 21, 2021]. https://doi.org/10.1109/ICACCI.2016.7732405

[29] R. Badi, B. Momin, "SCAR: Smart cart based on ARM algorithm and RFID technology," 2018 3rd IEEE International Conference on Recent Trends in Electronics, Information \& Communication Technology (RTEICT), 2018, pp. 2387-2392. Available: https://ieexplore. ieee.org/stamp/stamp.jsp?tp=\&arnumber=9012562. [Accessed March 20, 2021]. https://doi. org/10.1109/RTEICT42901.2018.9012562

[30] R. R. Vallabhuni, S. Lakshmanachari, G. Avanthi, V. Vijay, "Smart cart shopping system with an RFID interface for human assistance," 2020 3rd International Conference on Intelligent Sustainable Systems (ICISS), 2020, pp. 165-169. Available: https://ieexplore.ieee. org/stamp/stamp.jsp?tp=\&arnumber=9316102. [Accessed March 10, 2021]. https://doi. org/10.1109/ICISS49785.2020.9316102 


\section{Authors}

Tarig Faisal, Department of Electrical Engineering, Ruwais Colleges, Higher Colleges of Technology, Al Ruwais City, Abu Dhabi, UAE.

Moath Awawdeh, Department of Electrical Engineering, Ruwais Colleges, Higher Colleges of Technology, Al Ruwais City, Abu Dhabi, UAE.

Daniel Habte, Department of Electrical Engineering, Ruwais Colleges, Higher Colleges of Technology, Al Ruwais City, Abu Dhabi, UAE.

Hala Berhanu, Department of Electrical Engineering, Ruwais Colleges, Higher Colleges of Technology, Al Ruwais City, Abu Dhabi, UAE.

Kibrom Kifle, Department of Electrical Engineering, Ruwais Colleges, Higher Colleges of Technology, Al Ruwais City, Abu Dhabi, UAE.

Lia Misghina, Department of Electrical Engineering, Ruwais Colleges, Higher Colleges of Technology, Al Ruwais City, Abu Dhabi, UAE.

Anees Bashir, Department of Electrical Engineering, Ruwais Colleges, Higher Colleges of Technology, Al Ruwais City, Abu Dhabi, UAE.

Article submitted 2021-08-20. Resubmitted 2021-10-12. Final acceptance 2021-10-13. Final version published as submitted by the authors. 